NBER WORKING PAPER SERIES

\title{
INTERNATIONAL TRADE AND THE NEGOTIABILITY OF GLOBAL CLIMATE CHANGE AGREEMENTS
}

\author{
Yuezhou Cai \\ Raymond Riezman \\ John Whalley \\ Working Paper 14711 \\ http://www.nber.org/papers/w14711
}

\author{
NATIONAL BUREAU OF ECONOMIC RESEARCH \\ 1050 Massachusetts Avenue \\ Cambridge, MA 02138 \\ February 2009
}

The views expressed herein are those of the author(s) and do not necessarily reflect the views of the National Bureau of Economic Research.

NBER working papers are circulated for discussion and comment purposes. They have not been peerreviewed or been subject to the review by the NBER Board of Directors that accompanies official NBER publications.

(C) 2009 by Yuezhou Cai, Raymond Riezman, and John Whalley. All rights reserved. Short sections of text, not to exceed two paragraphs, may be quoted without explicit permission provided that full credit, including $\odot$ notice, is given to the source. 
International Trade and the Negotiability of Global Climate Change Agreements

Yuezhou Cai, Raymond Riezman, and John Whalley

NBER Working Paper No. 14711

February 2009

JEL No. F13,Q54

\begin{abstract}
$\underline{\text { ABSTRACT }}$
Country incentives to participate in cooperative arrangements which either fully or partially internalize climate change externalities from carbon emissions involve critical asymmetries. Small countries trade off own country costs of carbon mitigation actions against their own benefits from global improvements in climate which benefit all. Small countries thus have limited incentive to participate as their actions, while costly to them, have a significant impact on global temperature change which mainly benefits others. Here we build on the work of Shapley and Shubik (1969) which suggests that the core of a global warming game without transferable utility may be empty and use numerical simulation methods to analyse country incentives to participate in carbon emission limitation negotiations using a micro global warming structure related to that used by Uzawa(2003). We discuss how the presence of international trade in goods affects the willingness of countries to join international negotiations on climate change. We calibrate our simulation structure to business as usual scenarios for the period 2006-2036. We go significantly beyond the PAGE model relied on in the Stern (2006) report in capturing multi-country interactive effects on the benefit side of climate change mitigation. We show how the perceived severity of global climate change damage influences participation decisions, and importantly how international trade makes participation more likely.
\end{abstract}

Yuezhou Cai

Institute of Quantitative \& Technical Economics

Chinese Academy of Social Sciences

14th Floor, CASS Building

5 Jianguomennei Str., Beijing 100732

Beijing, China

caiyuezhou88@hotmail.com
John Whalley

Department of Economics

Social Science Centre

University of Western Ontario

London, Ontario N6A 5C2 CANADA

and NBER

jwhalley@uwo.ca

Raymond Riezman

Department of Economics

Henry B. Tippie College of Business

W360 PBB

University of Iowa

Iowa City, IA 52242-1000

raymond-riezman@uiowa.edu 


\section{Introduction}

We discuss how the presence of international trade influences country willingness to participate in global climate change negotiations and why. These negotiations are aimed at reducing global temperature change by having countries mutually agree to reduce carbon emissions and in this way jointly internalize the associated global externalities from own country emissions.In practice, what form actual negotiations take will depend on agreements struck between participants, including penalties on non-participants. Here, we limit our discussion to the participation decision and do not discuss the form that cooperative arrangements will take. We emphasize the potential contribution of international trade in facilitating individual country participation in negotiations.

Climate change is a classic global externality problem that has been analyzed either explicitly or implicitly by Shapley and Shubik (1969), Barrett (1994), Uzawa(1999) and others. Their research shows that small players (small countries in our case) have little incentive to participate in cooperative arrangements which either fully or partially internalize externalities unless there are side payments. This is because small countries bear the costs of their carbon mitigation actions, but being small the benefits from resulting improvements in global climate largely accrue elsewhere. Large countries will have more incentive to participate as their actions, which while costly to them, can have a significant impact on themselves via temperature change. This work on externality also emphasizes, as in Shapley and Shubik (1969), that the core of a game with global warming but without transferable utility may be empty.

Here, we present numerical simulation results which not only bear on these issues but also allow us to evaluate whether participation is made more likely by allowing for the presence of international trade. We follow an analytical structure of a global warming game originally due to Uzawa (1999), but unlike Uzawa transferable utility(or side payments) is not allowed. We first discuss the case with a single consumption good globally and allow country endowments to be either put aside to reduce global temperature change (i.e. reduce carbon emissions) or be consumed. For this structure, in the symmetric case there exists 
a critical country size such that countries larger than this are willing to participate and negotiate reductions in carbon emissions, while countries smaller than the critical size are not willing to do so. We then investigate the model implications for the asymmetric case using 2006 data on a series of large economies (US, EU, Japan, China, India, Russia, Brazil, and Rest of World) using a global structure and explore the role of preferences and other parameters on the critical country size for decisions on participation.

We use data on consumption and trade for the economies we analyze along with growth profiles for these countries, and various damage and temperature change assumptions for business as usual scenarios and undertake numerical investigation with our analytical structure. The base data is for a single 50 year period 2006-2056 with assumed yearly growth rates over the period. We use calibration to a temperature change function for prospective changes in temperature under a business as usual scenario out to both 2036 and 2056, and use various estimates of associated damage over the ranges as reported by Stern (2007) and Mendelsohn (2007).

We then generalize the analysis to the case of one good per country so as to allow for the presence of international trade in the analysis. We use this combined Armington trade and global warming model to investigate the impacts of international trade on the decision of individual countries to participate in global negotiations to reduce emissions. In this structure, the presence of trade produces positive terms of trade effects from lowered domestic sales of the own country goods, enhancing direct country gains from lowered temperatures from own country actions on global climate change. It also reduces the costs of actions since reductions in consumption are spread over many goods and so the forgoing marginal utility of consumption from consumption restraint is less adversely affected compared to the one homogeneous good case.

Our numerical results also show that countries that may not be willing to participate in the one good case may be willing to participate in the $\mathrm{N}$ good case with international trade. These results therefore suggest that international trade can be a positive factor in motivating participation in international negotiation on climate change.Our results also show that the incentive to join such negotiations varies greatly with the prospective size of damages. 


\section{A Theoretical Model of Climate Change Negotiation Participation}

Global warming negotiations aim at achieving joint carbon emission abatement in the presence of externality effects across countries. The first round of global negotiations in this vein concluded in Kyoto 1997, and now continue in the current post Bali road map negotiations set to conclude in Copenhagen in 2009 with agreement for the period after 2012. These negotiations aim to achieve joint mutual agreement to act, and will only conclude when all parties accept each others commitments. More detailed discussion of these negotiations is given in Walsh and Whalley (2008).

We focus on individual country incentives to participate in negotiation, rather than the outcome of such negotiations. Effectively,we investigate whether the core of the cooperative game represented by the country strategy space over possible actives on climate change is empty or not. We build on relevant literature on the core. In the no externality case, Scarf (1960) established the non emptiness of the core. Debreu and Scarf (1967) later showed how in a replica economy the core of the economy collapses to the competitive equilibrium, establishing a form of equivalence between the core and competitive equilibria. Shapley and Shubik (1969) showed by notes and example that the core of an economy with external diseconomies may be empty. In cases where own agent actions to internalize externalities (i.e. reduce carbon emissions) have little own effect (such as with small countries), but at substantial cost, there is little incentive to act or join cooperative arrangements. Shapley and Shubik (1969) implicitly discuss a case with non transferable utility, but where transferable utility is allowed (as in Uzawa (1999)) the non emptiness of the case will be reversed due to the joint gains from internalization.

This literature thus suggests that where side payments do not occur fully participatory collective global agreement on carbon emission reduction may not be feasible since the number of countries participating in the agreement would need to be small to achieve mutual agreement since each country can free-ride without any punishment.Sub global agreements 
with penalties by participants on non participants to force participation may be feasible, but we do not analyze these here.

The likelihood of positive participation also depends critically on the severity of damage from the externality. We later argue that as we introduce international trade between countries into the model it likely makes agreement easier to reach. We first set out the theoretical model. We begin with the one-good case, and then move to the $\mathrm{N}$ good, $\mathrm{N}$ country case. Empirically based analyses follow.

We first assume that there are $N$ countries in the world and each owns and consumes the same good. We will analyze a single period of a number of years during which each economy grows. We assume that consumption of the good by the country directly generates emissions of carbon which in turn raise global temperatures. countries receive positive utility from consumption but negative utility from temperature change. Countries thus have an upper bound on own consumption, and if they consumes less than the upper bound they experienced less temperature change. If they are small, their own actions have little or no effect on temperature change.

As we will later analyse the impacts of agreements to reduce carbon emissions over a given period of time, the single period model has been set up to cover a number of years, 50 . In this 50 year period, we focus on changes in consumption (use of one good) and utility, and measure change in these variables relative to the outcome of zero growth over the period. The utility function is thus defined over 50 year changes on consumption and temperature change. Potential use of the good reflects to changes in potential output from the economy over 50 years.

We first analyze a business as usual (BAU) scenario which reflects current observed growth rates remaining unchanged over 50 years with no global or single country emissions limitation initiatives in place. The actual change in consumption for each country $i$ over this time period $t$ relative to a stationary state is $\Delta R_{i}$, while the total potential output of each country is given by a $\Delta \bar{R}_{i}$. Countries can decide to consume less than their potential, but since global temperature change over the period is linked to global consumption consuming at less than potential reduces utility lowering global temperature change. Consumption in 
each country is given by $\Delta R_{i}<\Delta \bar{R}_{i}$, where $\Delta R_{i}$ defines actual consumption change over the model period, and $\Delta \bar{R}_{i}$ is potential consumption change. $\Delta \bar{R}=\sum \Delta \bar{R}_{i}$ is world potential consumption.

The utility of each country from both consumption and temperature change over the period is reflected in a utility change function with arguments given by its own change in consumption as well as the temperature change of the world, $\Delta T$. Damage from climate change thus appears in utility form, not as production damage as in many other papers.

Without loss of generality, we initially assume the utility change function for each country has a Cobb-Douglas form given by (1) and later use CES and alternative forms.

$$
\Delta U_{i}=\Delta U_{i}\left(\Delta R_{i}, \Delta T\right)=\Delta R_{i}^{\alpha} \cdot\left(\frac{C-\Delta T}{C}\right)^{\beta}
$$

In this specification $C$ can be thought of the global temperature change at which all economic activity ceases (say $10^{\circ} C$ ). In this case, as $\Delta T$ approaches $C$ utility utility goes to zero. In this form, as $\Delta T$ goes to zero there is no welfare impact of temperature change. Utility change over the model period (2006-2056) increases as temperature change falls. The share parameter $\beta$ reflects the severity of damage (in utility terms) from temperature change, which we later calibrate to various damage estimates from business as usual global temperature change reported by Stern (2006) and Mendelsoln (2007).

Global temperature change, in turn, is determined by the change in carbon emissions over the period across all countries in the model. We adopt a simple temperature change function and assume that emissions over the period by each country equal the change in consumption times country emissions intensity (emissions/GDP) so as to allow for differing emissions intensities by country. Defining the emissions intensity of country $i$ as $e_{i}$, we use a simple power function (2) for global temperature change due to changes in emissions by all countries over the model period.

$$
\Delta T=g\left(\sum e_{i} \Delta R_{i}\right)=a\left(\sum e_{i} \Delta R_{i}\right)^{b}+c
$$

In this structure, a carbon reduction commitment by a single country implies reduced 
change in consumption, and this has both negative and positive effects on utility change for the countries over the model period. On the one hand, a reduction in consumption change lowers utility change for the country by reducing consumption change, but on the other hand, country consumption change reductions lower global emissions and hence world temperature change, and increase the utility both of the country reducing the emissions and all other countries.

If the benefits of lowered global temperatures from own country actions are larger than the utility loss from reducing own consumption change, the country has an incentive to reduce its emissions, and if they can negotiate cooperatively with all other countries will be better off. We thus assume that in this case a country will be willing to participate in negotiations on mutual agreements to reduce emissions by all countries since larger positive welfare benefits will follow from collective actions. Were there negative benefits, in the absence of penalties on them from other countries who participate in joint action (which we assume) then the country has an incentive to free ride on the actions of others and opt out of negotiations.the analytical structure can be modified to capture agreed penalty structure of participants. We can use the same approach to also consider decisions by groups (or coalitions) of countries to enter into singular negotiations on a sub global group bases.

The algebra that reflects the participation decision of individual countries can be written from (1) as

$$
\frac{d \Delta U_{i}}{d \Delta R_{i}}=\frac{\partial \Delta U_{i}\left(\Delta R_{i}, \Delta T\right)}{\partial \Delta R_{i}}+\frac{\partial \Delta U_{i}\left(\Delta R_{i}, \Delta T\right)}{\partial \Delta T} \frac{\partial \Delta T}{\partial \Delta R_{i}} \leq 0
$$

and if $\frac{d \Delta U_{i}}{d \Delta R_{i}}$ is negative then participation will occur. For the Cobb-Douglas case this becomes

$$
\frac{d \Delta U_{i}}{d \Delta R_{i}}=\alpha\left(\frac{C-\Delta T}{C}\right)^{\beta} \Delta R_{i}^{\alpha-1}-\frac{\beta}{C} \Delta R_{i}^{\alpha}\left(\frac{C-\Delta T}{C}\right)^{\beta-1} a b e_{i}\left(\sum e_{i} \Delta R_{i}\right)^{b-1} \leq 0
$$




\section{Calibration and Data}

We calibrate our one good model to a base case business as usual (BAU) scenario for the period 2006-2056 for eight region country grouping, US, EU, Japan, China, India, Russia, Brazil and the rest of the world (ROW). We use measures of GDP growth over the period to determine the change in consumption by country over the period under BAU. We first assume that country growth rates in the period 2000-2056 remain unchanged over the whole period of 50 years between 2006 and 2056 and then use a discount rate of $1.5 \%$ to calculate the discounted present value of GDP over this period for each economy. We then calibrate a temperature change function for assumed BAU temperature change over the period drawn from key literature sources, including Stern (2006) and Mendelsohn (2007) and preferences for each country using alternative damage estimates for the same sources.

Using model parameters generated by calibration, we can then reduce own consumption for individual countries and regions by $1 \%$ and assess the sign of the welfare effect. From this sign, we then determine willingness to participate in global emission reduction negotiations.

We use data on 2006 GDP by country, 2000-2006 average growth rates and 2004 emissions intensity data to determine parameters $a, b$ and $c$ from equation (2) for a given BAU temperature change. We then use various estimates of damage from BAU emission increases to determine $\beta$ by calibration. These parameters then determine which countries satisfy the condition in equation (4) and thus, are willing to participate in a carbon reduction agreement.

Emissions data by country are for the year 2004 and at first projected to 2006 as the model base year for the period 2006-2056. The Stern review (2006) projects a "business as usual" (BAU) growth path of emissions which implies at approximately $2^{\circ} \mathrm{C}$ increase in average global temperature by the 2036 and a $5^{\circ} \mathrm{C}$ increase by 2056 . We use this BAU scenario for temperature change to calibrate our model temperature change function.In doing this, we

\footnotetext{
${ }^{1}$ The Stern Review (2006)projections are that even if the annual global flow of emissions remains unchanged, the global stock of GHG concentrations would still reach 550ppm $\mathrm{CO}_{2} e$ by 2050.In the Stern BAU paths, the annual flow of emissions is accelerating, and the level of 550ppm $\mathrm{CO}_{2} e$ could be reached as early as 2035, at which point there is 77-99 per cent of chance of global average temperature rise exceeding $2^{\circ} C$. If the level of 750ppm $\mathrm{CO}_{2} e$ is reached around 2050, then the temperature change will be near $5^{\circ} \mathrm{C}$ according to their projections.
} 
make the strong assumption that emission intensities will not change as we move forward in time and use current (2000-2006) unchanged country growth rates to calculate implied emissions. Later we discuss how relaxing this assumption affects our results.

The data used and the resulting calculations of model based measures (emissions, GDP change 2006-2056) for the BAU projection and used in calibration are reported in Table 1.

Table 1: GDP and Emissions Data and Projections to 2036 and 2056 (Trillions US\$/Billions of Metric Tons)

\begin{tabular}{|l|c|c|c|c|c|c|c|c|c|}
\hline & $\mathrm{US}$ & $\mathrm{EU}$ & Japan & China & India & Russia & Brazil & ROW & World \\
\hline GDP 2004 & 11.712 & 13.044 & 4.608 & 2.254 & 0.667 & 0.592 & 0.664 & 8.048 & 41.590 \\
\hline Emissions 2004 & 6.050 & 3.841 & 1.258 & 5.009 & 1.343 & 1.525 & 0.332 & 7.880 & 27.241 \\
\hline $\begin{array}{l}\text { Emission Inten- } \\
\text { sity 2004 }\end{array}$ & 0.517 & 0.294 & 0.273 & 2.222 & 2.012 & 2.577 & 0.500 & 0.979 & 0.655 \\
\hline GDP 2006 & 13.164 & 10.636 & 4.368 & 2.645 & 0.912 & 0.987 & 1.067 & 14.682 & \\
\hline Emissions 2006 & 6.800 & 3.132 & 1.193 & 5.877 & 1.835 & 2.544 & 0.534 & 14.376 & 36.289 \\
\hline $\begin{array}{l}\text { Actual Annual } \\
\text { Growth Rate }\end{array}$ & 2.657 & 1.956 & 1.652 & 9.568 & 6.833 & 6.745 & 3.104 & 3.662 & \\
\hline $\begin{array}{l}\text { Rate less 1.5\% for } \\
\text { discount }\end{array}$ & 1.117 & 0.426 & 0.127 & 7.924 & 5.230 & 5.144 & 1.557 & 2.107 & \\
\hline GDP 2056 & 22.943 & 13.158 & 4.656 & 119.763 & 11.666 & 12.120 & 2.311 & 41.641 & 228.258 \\
\hline $\begin{array}{l}\text { Emissions in } \\
\text { 2056 }\end{array}$ & 11.851 & 3.874 & 1.271 & 266.140 & 23.474 & 31.238 & 1.156 & 40.771 & 379.774 \\
\hline $\begin{array}{l}\text { GDP 2006-2036 } \\
\text { Net emissions } \\
\text { 2006-2036 }\end{array}$ & 471.310 & 341.074 & 133.673 & 318.879 & 66.327 & 70.673 & 41.055 & 618.453 & 174.270 \\
\hline $\begin{array}{l}\text { GDP 2006-2056 } \\
\text { 2006-2056 emissions }\end{array}$ & 885.060 & 593.877 & 225.669 & 1595.092 & 216.377 & 227.567 & 81.131 & 1306.574 & 941.996 \\
\hline
\end{tabular}

GDP and emissions data by country for 2004 are used to calculate emissions intensities. Emission intensities, $e_{i}$, are calculated as emissions divided by GDP and are reported in row three. Row four reports GDP in 2006. Row five reports calculations of emissions in 2006 using the 2006 measures of GDP and the emission intensities calculated from 2004 data. Average country/region growth rates for the period 2000-2006 are reported in row six of Table 1. Row seven reports the annual growth rates we use in our calculation for a BAU scenario over the period 2006-2056 with a reduction of 1.5 percentage points for discounting 
in our projections. Row eight reports GDP projections for 2056 based on the 2006 GDP and the assumed growth rates. Using an assumption of constant emissions intensities gives us row nine the emissions projection for each country/region in 2056. Rows ten and eleven report computed GDP and emissions for the 2 periods 2006-2036 and 2006-2056. The result of these calculations are that in the BAU scenario net emissions of carbon would accumulate to about 942 billion tons over the period of 2006-2036 and 4766 billion metric tons over the period of 2006-2056.

We use these emission changes over the period to solve for the values of the parameters in the temperature change function using equation (2). Temperature change over the period is written as a function of the emissions change over the same period. We use a power function of accumulated emissions over the period. Using the data for 2006,2036, and 2056 in the above table,and assuming the temperature change at these three points to be $0^{\circ} \mathrm{C}, 2^{\circ} \mathrm{C}$, and $5^{\circ} \mathrm{C}$ respectively, we can solve for the values of parameters $a, b$, and $c$.

$$
\begin{gathered}
0=a(36.289-36.289)^{b}+c \\
2=a(941.996)^{b}+c \\
5=a(4765.585)^{b}+c
\end{gathered}
$$

Solving these equations for the parameters $a, b$, and $c$ yields values of $0.0417,0.5652$ and 0 . Substituting these values to equation (2), yields:

$$
\Delta T=g\left(\sum e_{i} \Delta R_{i}\right)=0.0417\left(\sum e_{i} \Delta R_{i}\right)^{0.565}
$$

The final step in our calibration is to generate values for the parameters $\alpha$ and $\beta$ in the utility function. As noted earlier, we normalize $\alpha$ and $\beta$ to sum to one to preserve linear homogeneity so we can more easily calculate money metric measures of welfare change.These parameters for the model are calibrated using literature sources (Stern, 2006; Mendelsohn, 
2007). Using the Stern Review (2005), Mendelsohn (2007) and other literature estimates of the damage cost of emissions along a business-as-usual (BAU) path in GDPterms, we treat these as utility change of the same proportion and use these estimates to calibrate the model parameters.

A wide range of estimates of damage for BAU emissions growth can be found in various sources, ranging from 5 to 49.5 percent of GDP. We alternatively treat these as utility losses in a number of calculations with changed damage estimates. For each damage estimate assumed, we recalibrate the model parameters and compute the utility parameters that would give rise to each of the implicit utility reductions. Without temperature change, the utility change function can be written as $\Delta U_{i}^{*}=\Delta R_{i}^{\alpha}$. In the presence of temperature change damage, we have $\Delta U_{i} / \Delta U_{i}^{*}=((C-\Delta T) / C)^{\beta}$. These equations can be used to calibrate the parameters $\alpha$ and $\beta$ for different damage cost scenarios with a temperature change $\Delta T$ of $5^{\circ} \mathrm{C}$ between 2006 and 2056. The value change for $C$ is important since the smaller is $C$, the larger the massive value of damage that the model will allow in Calibration. We use $C=10$, which then be used in sensitivity analysis. Table 2 reports the calibrated preference parameters under alternative damage assumptions.

Table 2: Calibrated Preference Parameters Under Alternative Damage Assumption

\begin{tabular}{|c|r|r|}
\hline Assumed Utility Loss over the Period due to BAU Temperature Change & $\alpha$ & $\beta$ \\
\hline $5.0 \%$ & 0.9260 & 0.0740 \\
\hline $10.0 \%$ & 0.8480 & 0.1520 \\
\hline $20.0 \%$ & 0.6781 & 0.3219 \\
\hline $30.0 \%$ & 0.4854 & 0.5146 \\
\hline $35.0 \%$ & 0.3785 & 0.6215 \\
\hline $37.5 \%$ & 0.3219 & 0.6781 \\
\hline $40.0 \%$ & 0.2630 & 0.7370 \\
\hline $45.0 \%$ & 0.1375 & 0.8625 \\
\hline $46.0 \%$ & 0.1110 & 0.8890 \\
\hline $47.0 \%$ & 0.0841 & 0.9159 \\
\hline $48.0 \%$ & 0.0566 & 0.9434 \\
\hline $49.0 \%$ & 0.0286 & 0.9714 \\
\hline $49.5 \%$ & 0.0144 & 0.9856 \\
\hline
\end{tabular}




\section{Experiments Exploring Global Carbon Reduction Ne- gotiation Participation in the One Good Case.}

We next execute counterfactuals using the model. We first consider what happens to welfare if each country reduces separately consumption by $1 \%$. We later consider cases of joint reduction. We use a time horizon of fifty years so that the calculation for each country captures the trade off between a reduction of output by $1 \%$ over the whole 50 year period and a lowered global temperature change over fifty years. In each case we compute the change in utility for each country. A positive number implies that the own country benefit of lowered temperature change over fifty years is larger than the utility cost of the own country consumption reduction. This implies that the country will be willing to enter into a carbon reduction agreement whereby it agrees to reduce its own consumption since there is no incentive to depart from a collective agreement.

The calculations we make for the one good case which assumes that there is no international trade are reported below in Table 3. Each row reports the results using different assumptions regarding the damage from a BAU temperature increase over the period. Row one assumes a $5 \%$ utility loss, row two a $10 \%$ utility loss, row three a $20 \%$ utility loss, row four a $30 \%$ utility loss, row five a $35 \%$ utility loss, and so on up to the $49.5 \%$ loss at the high end of the range we use following literature estimates. Looking at row thirteen we see that the US, China, India, and Russia in some cases benefit from own country consumption reductions and hence would participate in negotiations on emissions reduction, but for this to occur the cost damage in emissions reduction of $49.5 \%$ must apply. The US, China and the other countries by 2056 are relatively large so their reduction in consumption has a significant effect on global temperatures. For smaller countries, a reduction in consumption yields little reduction in global temperatures.

Looking at row five if the utility damage cost of a $5^{\circ} \mathrm{C}$ temperature increase is assumed to be $35 \%$ no country is willing to enter into a carbon reduction agreement. When the cost rises to $40 \%$ then China is willing to reduce carbon emissions. As the cost rises above $40 \%$, 
more countries are willing to participate in the agreement. These results thus suggest that for a given level of damage larger countries are more willing to participate than smaller one. Also, the more the damage associated with temperature increases the more countries are willing to participate. They also point to participation in negotiations only occurring for high levels of damage from carbon emissions.

\section{Table 3: Utility change for $1 \%$ decrease in consumption change for each national economy relative to BAU, 2006-2056}

\begin{tabular}{|c|c|c|c|c|c|c|c|c|}
\hline Damage & US & EU & Japan & China & India & Russia & Brazil & ROW \\
\hline $5.0 \%$ & -5.2138 & -3.8625 & -1.7368 & -7.9374 & -1.2979 & -1.3590 & -0.5584 & -7.1531 \\
\hline $10.0 \%$ & -2.9634 & -2.4374 & -1.3090 & -3.7493 & -0.7514 & -0.7831 & -0.3742 & -3.7606 \\
\hline $20.0 \%$ & -0.8376 & -0.8660 & -0.6849 & -0.6795 & -0.2206 & -0.2273 & -0.1516 & -0.8928 \\
\hline $30.0 \%$ & -0.1837 & -0.2469 & -0.3032 & -0.0759 & -0.0501 & -0.0508 & -0.0501 & -0.1583 \\
\hline $35.0 \%$ & -0.0740 & -0.1155 & -0.1811 & -0.0158 & -0.0204 & -0.0204 & -0.0255 & -0.0558 \\
\hline $37.5 \%$ & -0.0443 & -0.0749 & -0.1337 & -0.0044 & -0.0123 & -0.0121 & -0.0173 & -0.0308 \\
\hline $40.0 \%$ & -0.0250 & -0.0461 & -0.0944 & 0.0009 & -0.0069 & -0.0067 & -0.0111 & -0.0158 \\
\hline $45.0 \%$ & -0.0058 & -0.0132 & -0.0361 & 0.0032 & -0.0015 & -0.0013 & -0.0035 & -0.0025 \\
\hline $46.0 \%$ & -0.0039 & -0.0093 & -0.0273 & 0.0031 & -0.0009 & -0.0008 & -0.0025 & -0.0013 \\
\hline $47.0 \%$ & -0.0024 & -0.0062 & -0.0193 & 0.0029 & -0.0005 & -0.0004 & -0.0017 & -0.0005 \\
\hline $48.0 \%$ & -0.0012 & -0.0036 & -0.0121 & 0.0026 & -0.0002 & -0.0001 & -0.0010 & 0.0001 \\
\hline $49.0 \%$ & -0.0004 & -0.0015 & -0.0057 & 0.0024 & 0.0001 & 0.0002 & -0.0004 & 0.0005 \\
\hline $49.5 \%$ & 0.0000 & -0.0007 & -0.0027 & 0.0022 & 0.0002 & 0.0003 & -0.0002 & 0.0006 \\
\hline
\end{tabular}

We have also made calculations of the utility gain or loss relative to the BAU path for groups of countries, or coalitions. If groups of countries pre-commit to jointly reduce their consumption by 1\% (and hence emissions) then the impacts of joint actions on temperature change are larger, and coalitions of countries would be more willing to participate in global climate change negotiations. In Table 4, the levels of damage at which participation occurs increase, but it striking that even for large coalitions (such as India, China, Japan) the damage levels remain very high before participation occurs. 
Table 4: Utility change for $1 \%$ decrease in consumption change for sub global coalitions relative to BAU, 2006-2056

\begin{tabular}{|c|c|c|c|}
\hline Assumed Utility Damage for $5^{\circ} \mathrm{C}$ temperature change & US-EU-Japan & BRIC & Ind.-Chi.-Jap. \\
\hline $5.0 \%$ & -16.8341 & -11.5091 & -10.0273 \\
\hline $10.0 \%$ & -7.4474 & -5.2263 & -5.5136 \\
\hline $20.0 \%$ & -1.1629 & -0.8560 & -1.4496 \\
\hline $30.0 \%$ & -0.1062 & -0.0782 & -0.2927 \\
\hline $35.0 \%$ & -0.0179 & -0.0108 & -0.1126 \\
\hline $37.5 \%$ & -0.0033 & 0.0003 & -0.0657 \\
\hline $40.0 \%$ & 0.0028 & 0.0046 & -0.0362 \\
\hline $45.0 \%$ & 0.0043 & 0.0050 & -0.0079 \\
\hline $46.0 \%$ & 0.0040 & 0.0045 & -0.0052 \\
\hline $47.0 \%$ & 0.0036 & 0.0041 & -0.0031 \\
\hline $48.0 \%$ & 0.0032 & 0.0036 & -0.0016 \\
\hline $49.0 \%$ & 0.0028 & 0.0032 & -0.0004 \\
\hline $49.5 \%$ & 0.0026 & 0.0030 & 0.0000 \\
\hline
\end{tabular}

We have also examined the impact results of using different time horizons for countries to analyze participation decisions. The BAU scenario we use for the period 2006-2036 is that global temperatures will rise $2^{\circ} \mathrm{C}$ by 2036, and we use the same calibration as above only now for the time period 2006-2036.

The results for the two periods 2006-2036 and 2006-2056 are reported in Table 5 below. Results under the A heading are the results for period 2006-2036. Values under the B heading are for the period 2006-2056. These are taken directly from Table 2.Table 5 results imply that the utility change values are uniformly higher for the case 2006-2056 than for 2006-2036.

Looking at Table 5 and comparing columns $\mathrm{A}$ and $\mathrm{B}$ it is clear that the values in B, column indicating the longer time horizon, are larger than the values in column A. This implies that moving to a longer time horizon increases willingness to participate in carbon 
reduction initiatives.In the 2036 time frame, only when the utility loss reaches $48 \%$ will China be willing to participate in the carbon reduction agreements. While in the 2056 lime frame, China will be willing to participate in carbon reduction agreements under $48 \%$ utility loss scenario.

Table 5: Utility change for $1 \%$ decrease in consumption change for each national economy under BAU, 2006-2036and 2006-2056

\begin{tabular}{|c|c|c|c|c|c|c|c|c|c|}
\hline Cost & & US & $\mathrm{EU}$ & Japan & China & India & Russia & Brazil & ROW \\
\hline \multirow[t]{2}{*}{$5.0 \%$} & $\mathrm{~A}$ & -4.8184 & -3.3113 & -3.4216 & -2.2192 & -0.5548 & -0.4001 & -0.4136 & -5.5742 \\
\hline & B & -5.2138 & -3.8625 & -1.7368 & -7.9374 & -1.2979 & -1.3590 & -0.5584 & -7.1531 \\
\hline \multirow[t]{2}{*}{$10.0 \%$} & $\mathrm{~A}$ & -3.1026 & -2.3718 & -2.9208 & -1.2930 & -0.3751 & -0.2692 & -0.3145 & -3.3472 \\
\hline & B & -2.9634 & -2.4374 & -1.3090 & -3.7493 & -0.7514 & -0.7831 & -0.3742 & -3.7606 \\
\hline \multirow[t]{2}{*}{$20.0 \%$} & $\mathrm{~A}$ & -1.1514 & -1.1106 & -2.0208 & -0.3836 & -0.1547 & -0.1097 & -0.1677 & -1.0652 \\
\hline & B & -0.8376 & -0.8660 & -0.6849 & -0.6795 & -0.2206 & -0.2273 & -0.1516 & -0.8928 \\
\hline \multirow[t]{2}{*}{$30.0 \%$} & $\mathrm{~A}$ & -0.3446 & -0.4333 & -1.2452 & -0.0872 & -0.0521 & -0.0363 & -0.0758 & -0.2664 \\
\hline & B & -0.1837 & -0.2469 & -0.3032 & -0.0759 & -0.0501 & -0.0508 & -0.0501 & -0.1583 \\
\hline \multirow[t]{2}{*}{$35.0 \%$} & A & -0.1654 & -0.2412 & -0.8998 & -0.0351 & -0.0267 & -0.0184 & -0.0458 & -0.1151 \\
\hline & B & -0.0740 & -0.1155 & -0.1811 & -0.0158 & -0.0204 & -0.0204 & -0.0255 & -0.0558 \\
\hline \multirow[t]{2}{*}{$37.5 \%$} & A & -0.1087 & -0.1716 & -0.7365 & -0.0207 & -0.0181 & -0.0124 & -0.0340 & -0.0713 \\
\hline & B & -0.0443 & -0.0749 & -0.1337 & -0.0044 & -0.0123 & -0.0121 & -0.0173 & -0.0308 \\
\hline \multirow[t]{2}{*}{$40.0 \%$} & A & -0.0678 & -0.1164 & -0.5791 & -0.0113 & -0.0117 & -0.0079 & -0.0242 & -0.0416 \\
\hline & B & -0.0250 & -0.0461 & -0.0944 & 0.0009 & -0.0069 & -0.0067 & -0.0111 & -0.0158 \\
\hline \multirow{2}{*}{$45.0 \%$} & A & -0.0197 & -0.0409 & -0.2805 & -0.0019 & -0.0036 & -0.0023 & -0.0093 & -0.0100 \\
\hline & B & -0.0058 & -0.0132 & -0.0361 & 0.0032 & -0.0015 & -0.0013 & -0.0035 & -0.0025 \\
\hline \multirow[t]{2}{*}{$46.0 \%$} & A & -0.0140 & -0.0303 & -0.2230 & -0.0009 & -0.0026 & -0.0016 & -0.0071 & -0.0066 \\
\hline & B & -0.0039 & -0.0093 & -0.0273 & 0.0031 & -0.0009 & -0.0008 & -0.0025 & -0.0013 \\
\hline \multirow[t]{2}{*}{$47.0 \%$} & A & -0.0092 & -0.0210 & -0.1664 & -0.0002 & -0.0017 & -0.0010 & -0.0050 & -0.0039 \\
\hline & B & -0.0024 & -0.0062 & -0.0193 & 0.0029 & -0.0005 & -0.0004 & -0.0017 & -0.0005 \\
\hline \multirow[t]{2}{*}{$48.0 \%$} & A & -0.0053 & -0.0129 & -0.1103 & 0.0003 & -0.0009 & -0.0005 & -0.0031 & -0.0018 \\
\hline & B & -0.0012 & -0.0036 & -0.0121 & 0.0026 & -0.0002 & -0.0001 & -0.0010 & 0.0001 \\
\hline \multirow[t]{2}{*}{$49.0 \%$} & A & -0.0021 & -0.0059 & -0.0549 & 0.0007 & -0.0003 & -0.0001 & -0.0015 & -0.0002 \\
\hline & B & -0.0004 & -0.0015 & -0.0057 & 0.0024 & 0.0001 & 0.0002 & -0.0004 & 0.0005 \\
\hline \multirow[t]{2}{*}{$49.5 \%$} & A & -0.0008 & -0.0027 & -0.0274 & 0.0009 & 0.0000 & 0.0001 & -0.0007 & 0.0005 \\
\hline & B & 0.0000 & -0.0007 & -0.0027 & 0.0022 & 0.0002 & 0.0003 & -0.0002 & 0.0006 \\
\hline
\end{tabular}

Note: A-2006-2036; B-2006-2056. 


\section{International Trade and Global Emission Reduction Negotiation Participation}

We next consider the effect of international trade on the willingness of countries to participate in carbon reduction agreements. As before, we assume there are $N$ countries in the world, however now use an Armington structure in which each good in each country is different, yielding an $N$ good $N$ country model. We use nested CES preferences for consumption change in each country where the nesting structure covers two stages.At the first level, preferences are again defined over $\Delta R_{i}$ and $\Delta T$. At the second stage $\Delta R_{i}$ is a composite of the individual country goods, rather than a single homogeneous good. As before, a larger $\Delta R_{i}$ and lower $\Delta T$ give rise to higher utility. In the one-good case, there is no international trade and country use of their good equals consumption for the country. In the trade case, own country consumption change is no longer equal to potential consumption change using its own good. Some of their own good is exported and own goods of other countries are imported. Consumption change is thus a composite of goods from different countries. The structure of the resulting trade equilibrium model with temperature change can be divided into three levels or parts.

\section{Temperature Change and Top Level Utility Function}

At the first top level, the function of forms for utility and temperature change are the same as in the one-good case.

$$
\begin{gathered}
\Delta U_{i}=\Delta U_{i}\left(\Delta R C_{i}, \Delta T\right)=\Delta R C_{i}^{\alpha} \cdot\left(\frac{C-\Delta T}{C}\right)^{\beta} \\
\Delta T=g\left(\sum e_{i} \Delta R S_{i}\right)=a\left(\sum e_{i} \Delta R S_{i}\right)^{b}+c
\end{gathered}
$$

In this case, however $\Delta R C_{i}$ represents the composite consumption change in the good for 
each country $i$, while $\Delta R S_{i}$ represents the use of the own good for each country $i$. Because of trade $\Delta R C_{i} \leq \Delta R S_{i}$, unlike in the one good case where $\Delta R C_{i}=\Delta R S_{i}$

\section{Composite Final Consumption Goods by country}

The composite consumption good $\Delta R C_{i}$ is a CES function of domestic and imported consumption goods, which is similar that used in the nested CES Armington models (see Whalley (1985)). The model effectively becomes an Armington $N \operatorname{good} N$ country pure trade economy in which the endowment is variable.

The resulting sub-utility maximization problem can be written as

$$
\begin{gathered}
\text { Max } \Delta R C_{i}=\left(\left(\alpha_{i}^{d}\right) \Delta D(i)^{\frac{\sigma-1}{\sigma}}+\left(\alpha_{i}^{m}\right) \Delta M(i)^{\frac{\sigma-1}{\sigma}}\right)^{\frac{\sigma}{\sigma-1}} \\
\text { s.t. } p d(i) \Delta D(i)+p m(i) \Delta M(i)=\operatorname{Inc}(i) \\
\operatorname{Inc}(i)=p(i) \Delta R S_{i}
\end{gathered}
$$

Where $\Delta D(i)$ and $\Delta M(i)$ represent consumption of the domestic and a composited imported goods respectively. The composition of $\Delta M(i)$ is determined by a third level of nesting in the CES preferences in the model.

\section{Composite of Imported Goods}

The CES composite commodities at the third level of nesting are composites of imported goods for each country. Given that each country has one good it can sell, but $N-1$ goods

it can consume, the CES composite of other goods defines an import composite. This can be represented as the outcome of a sub-utility maximization exercise. 


$$
\begin{gathered}
\operatorname{Max} \quad \Delta M(i)=\left(\sum_{i \neq j}\left(\gamma_{i}^{j}\right)^{\frac{1}{\theta}}\left(\Delta R M_{i}^{j}\right)^{\frac{\theta-1}{\theta}}\right)^{\frac{\theta}{\theta-1}} \\
\text { s.t. } \quad \sum_{i \neq j} p(j) \Delta R M_{i}^{j}=p m(i) \Delta M(i)
\end{gathered}
$$

where $\Delta R M(i)$ is the imported good $i$ by country $j$ and $p m(i)$ is the composite import price for country $i$. These reflect CES sub-utility maximization problems and are given as:

$$
\begin{aligned}
& \Delta R M_{i}^{j}=\frac{\gamma_{i}^{j} p m(i) \Delta M(i)}{p(j)^{\theta}\left(\sum_{i \neq j}\left(\gamma_{i}^{j}\right)\left(p(i)^{1-\theta}\right)\right.} \\
& p m(i)=\left(\sum_{i \neq j}\left(\gamma_{i}^{j}\right)^{\frac{1}{\theta}}\left(p(j)^{\theta}\right)^{1-\theta}\right)^{\frac{1}{1-\theta}}
\end{aligned}
$$

As we have only one good for use in each country, the price of basic domestic goods $p(i)$ difine the imput prices by purchases of goods. The model can be amended to also capture tariffs or other import barriers in country $i$.

\section{Trade Equilibrium}

In this structure, given values of $\Delta R S_{i}$ a trade equilibrium is given by prices $p_{1} \ldots p_{N}$ for which global market clear, ie

$$
\sum_{i=j}\left(\Delta M_{i}^{j}\right)+\Delta D_{i}=\Delta R S_{i} \quad(i=1, \cdots, N)
$$

In this structure, unlike in the one good case, as countries contemplate participating in global environmental negotiations if they reduce emissions by reducing $\Delta R S_{i}$ there will be general equilibrium implications on all prices and quantities. Importantly, a reduction in $\Delta R S_{i}$ will typically cause the price of the own good $i$ to rise giving a terms of trade gain to the country making the emissions $\left(\Delta R S_{i}\right)$ reduction. This will spread the burden of the country emissions reduction to all other countries reducing the own country cost of emissions 
reductions to the country making the reduction. This will, in turn, increase the willingness to participate in global emissions reductions negotiations 2 .

\section{Comparison of Trade and Non-trade Cases of Participation De- cision Analysis}

Using the nested trade-consumption model, composite consumption $\Delta R C_{i}$ will change as $\Delta R S_{i}$ changes. Similar to the one-good simple case, we can evaluate the utility impact of a change in $\Delta R S_{i}$. Once again there will be a direct effect on consumption change, but now on consumption change of all $N$ goods through trade, and once again a temperature change. These effects will determine participation in global environmental negotiations.

We note that it is difficult to compare the trade and non-trade cases precisely, and for two reasons. First, when trade is omitted the demand of each country in the simple one-good case is its own good. With trade introduced in the model, the demand of each country is the nested CES composed commodity, and the use of the own good of each country enters the budget constraint. Thus,given the same use of own country good, consumption change is different between the trade and non-trade cases.

Second, what is exogenous is different between the two cases. In the non-trade case, the maximum consumption change of the world is exogenous, and the consumption of each country can vary. In the trade case, the own good use of each country is exogenous. But consumption changes as the price of each good changes and affects the budget constraint for each country.

\section{Simulation Results for the Trade Case with 2006-2056 Data Base and Comparison to the Non-trade Case}

To analyze participation decisions in the with trade model and make comparisons to the

\footnotetext{
${ }^{2}$ If a two good equilibria were used for each country and emissions reduction initiatives involved increased carbon (energy) costs which for some countries affected export industries, terms of trade effects effects could work in the opposite direction for some conditions. We are grateful for Bob Staiger for this comment.
} 
one good no trade case, we calibrate the with trade model to the same GDP and emissions data but now add trade and also calibrate the nested CES preference functions by country.

We use bilateral trade data as well as the same GDP data for 2006 for each country, and project forward using annual growth rate data as for the one good model. We assume the trade structure to be unchanged in proportional terms for the whole period of 2006-2056. For each country's change in $\Delta R S_{i}$, there is a then a new equilibrium set of prices and new trade volumes and hence a value for $\Delta U_{i}$. These we take once again to determine decisions on participation in global environmental negotiations.

The results reported in Table 6 reveal that generally speaking taking international trade into account makes carbon reduction agreement participation more likely. Comparing the A (no trade) and B (with international trade) one can see from Table 6 that the values in the B column are generally larger than the values in the A row. Higher values indicate more benefits from reducing your own output hence participation is more likely. For the US, in the trade model case participation occurs with only $10 \%$ damage, while for the no trade case no participation occurs. similar change in participation decisions occurs for other regions. The intuition for these results is that reducing use of a country own good raises its price, thereby improving their terms of trade making carbon reduction negotiation participation more attractive than in the no trade case. 
Table 6: Analysis for Utility Change for 1\% decrease in consumption of own good by each National Economy for One good and $N$ good(with trade)cases for the period 2006-2056

\begin{tabular}{|c|c|c|c|c|c|c|c|c|c|}
\hline Cost & & US & $\mathrm{EU}$ & Japan & China & India & Russia & Brazil & ROW \\
\hline \multirow[t]{2}{*}{$5.0 \%$} & $\mathrm{~A}$ & -5.2138 & -3.8625 & -1.7368 & -7.9374 & -1.2979 & -1.3590 & -0.5584 & -7.1531 \\
\hline & B & -0.2345 & -0.3292 & -0.1917 & -0.6179 & -0.0740 & -0.2377 & -0.0825 & -0.7354 \\
\hline \multirow[t]{2}{*}{$10.0 \%$} & $\mathrm{~A}$ & -2.9634 & -2.4374 & -1.3090 & -3.7493 & -0.7514 & -0.7831 & -0.3742 & -3.7606 \\
\hline & B & 0.0279 & -0.0834 & -0.0797 & 0.0488 & -0.0004 & -0.0974 & -0.0375 & -0.1759 \\
\hline \multirow[t]{2}{*}{$20.0 \%$} & A & -0.8376 & -0.8660 & -0.6849 & -0.6795 & -0.2206 & -0.2273 & -0.1516 & -0.8928 \\
\hline & B & 0.1174 & 0.0755 & 0.0387 & 0.2017 & 0.0304 & 0.0003 & 0.0019 & 0.0837 \\
\hline \multirow[t]{2}{*}{$30.0 \%$} & $\mathrm{~A}$ & -0.1837 & -0.2469 & -0.3032 & -0.0759 & -0.0501 & -0.0508 & -0.0501 & -0.1583 \\
\hline & B & 0.0576 & 0.0602 & 0.0629 & 0.0791 & 0.0167 & 0.0093 & 0.0079 & 0.0477 \\
\hline \multirow[t]{2}{*}{$35.0 \%$} & $\mathrm{~A}$ & -0.0740 & -0.1155 & -0.1811 & -0.0158 & -0.0204 & -0.0204 & -0.0255 & -0.0558 \\
\hline & B & 0.0315 & 0.0394 & 0.0544 & 0.0397 & 0.0096 & 0.0065 & 0.0063 & 0.0258 \\
\hline \multirow[t]{2}{*}{$37.5 \%$} & $\mathrm{~A}$ & -0.0443 & -0.0749 & -0.1337 & -0.0044 & -0.0123 & -0.0121 & -0.0173 & -0.0308 \\
\hline & B & 0.0218 & 0.0297 & 0.0472 & 0.0268 & 0.0069 & 0.0050 & 0.0052 & 0.0177 \\
\hline \multirow[t]{2}{*}{$40.0 \%$} & A & -0.0250 & -0.0461 & -0.0944 & 0.0009 & -0.0069 & -0.0067 & -0.0111 & -0.0158 \\
\hline & B & 0.0143 & 0.0211 & 0.0386 & 0.0175 & 0.0047 & 0.0036 & 0.0040 & 0.0115 \\
\hline \multirow[t]{2}{*}{$45.0 \%$} & $\mathrm{~A}$ & -0.0058 & -0.0132 & -0.0361 & 0.0032 & -0.0015 & -0.0013 & -0.0035 & -0.0025 \\
\hline & B & 0.0046 & 0.0079 & 0.0194 & 0.0067 & 0.0017 & 0.0015 & 0.0017 & 0.0040 \\
\hline \multirow[t]{2}{*}{$46.0 \%$} & A & -0.0039 & -0.0093 & -0.0273 & 0.0031 & -0.0009 & -0.0008 & -0.0025 & -0.0013 \\
\hline & B & 0.0034 & 0.0059 & 0.0155 & 0.0054 & 0.0013 & 0.0012 & 0.0013 & 0.0031 \\
\hline \multirow[t]{2}{*}{$47.0 \%$} & $\mathrm{~A}$ & -0.0024 & -0.0062 & -0.0193 & 0.0029 & -0.0005 & -0.0004 & -0.0017 & -0.0005 \\
\hline & $\mathrm{B}$ & 0.0024 & 0.0042 & 0.0115 & 0.0043 & 0.0010 & 0.0009 & 0.0010 & 0.0023 \\
\hline \multirow[t]{2}{*}{$48.0 \%$} & $\mathrm{~A}$ & -0.0012 & -0.0036 & -0.0121 & 0.0026 & -0.0002 & -0.0001 & -0.0010 & 0.0001 \\
\hline & B & 0.0015 & 0.0026 & 0.0076 & 0.0034 & 0.0007 & 0.0007 & 0.0006 & 0.0017 \\
\hline \multirow[t]{2}{*}{$49.0 \%$} & A & -0.0004 & -0.0015 & -0.0057 & 0.0024 & 0.0001 & 0.0002 & -0.0004 & 0.0005 \\
\hline & $\mathrm{B}$ & 0.0008 & 0.0013 & 0.0038 & 0.0027 & 0.0005 & 0.0005 & 0.0003 & 0.0012 \\
\hline \multirow[t]{2}{*}{$49.5 \%$} & $\mathrm{~A}$ & 0.0000 & -0.0007 & -0.0027 & 0.0022 & 0.0002 & 0.0003 & -0.0002 & 0.0006 \\
\hline & B & 0.0005 & 0.0007 & 0.0019 & 0.0024 & 0.0004 & 0.0004 & 0.0002 & 0.0010 \\
\hline
\end{tabular}

Note: A-no international trade (one good) case; B-with international trade (N good) case. 


\section{Concluding Remarks}

We consider the incentives for individual countries to engage in global full participation negotiations on carbon reduction agreements. To reduce carbon emissions a country reduces its consumption of its own good. This yeilds two counteracting effects. The direct effect of reducing its own consumption is that consumption declines and with its utility. However, reducing carbon emissions also lowers global temperatures and that increases utility. In a simple one good model the trade off between these two effects determines incentives to free ride (assuming no penalties on free rides), but in the $N$ goods case with trade changes in a country's term of trade also come into play.

Calibrating no trade and with trade models to 2006-2056 business as usual scenarios reveals an unwillingness by countries in global climate change negotiations to participate unless the damage from climate change is large. Larger countries are more likely to participate because a given percentage reduction in output will result in a larger reduction in global temperatures the larger the country. Longer time horizons also lead to greater willingness to participate for rapidly growing countries. But, the presence of international trade makes carbon reduction agreements more likely because reducing the output of your own (export) good has a positive term of trade effect which reduces the cost of output reduction.

We conclude by noting that the analytical structure for numerical simulation analysis of carbon reduction initiative impacts which we present here also has wider application. This framework can also be used to analyze the links between penalties and participation, such as trade barriers used to force compliance with sub-group initiatives, or the size of accompanying financial transfers needed to induce participation. These and other extensions we plan to explore in following work, as well as modifying of the cost function used for emissions reduction. 


\section{References}

[1] Barrett, Scott,1994. Self-Enforcing International Environmental Agreements.Oxford Economic Papers, New Series, Vol. 46, Special Issue on Environmental Economics, pp.878-894.

[2] Botteon, Michele and Carlo Carraro,1997.Burden-Sharing and Coalition Stability in Environmental Negotiations with Asymmetric Countries.in C. Carraro, ed.,International Environmental Negotiations: Strategic Policy Issues, Edward Elgar, Cheltenham.

[3] Chen Zhiqi,1997.Negotiating an Agreement on Global Warming: A Theoretical Analysis.Journal of Environmental Economics and Management, 32,170-188.

[4] Chen Zhiqi,1997.Can Economic Activities Lead to Climate Chaos? An Economic Analysis of Global Warming.The Canadian journal of Economics, Vol.30, No.2, pp349-366.

[5] Debreu, Gerard and Herbert Scarf,1963. A Limit Theorem on the core of an Economy.International Economic Review, Vol. 4, No.3. (Sep., 1963), pp. 235-246.

[6] Mendelsohn, Robert, O,2006.A Critique of the Stern Report, Regulation.(Winter 20062007), pp.42-46.

[7] Scarf, Herbert E ,1967. The Core of an N Person Game.Econometrica, Vol.35, No.1. (Jan., 1967), pp. 50-69.

[8] Shapley, Lloyd,S., Shubik, Martin ,1969. On the Core of an Economic System with Externalities. American Economic Review, Vol. 59, No. 4, pp678-684.

[9] Stern,Nicholas ,2006.Stern Review on the Economics of Climate Change. London, UK: Her Majesty's Treasury.

[10] Uzawa, H. ,1999.Global Warming as a Cooperative Game. Environmental Economics and Policy Studies, 1999, Vol.2, pp.1-37.

[11] Uzawa, H. ,2003.Economic Tneory and Global Warming. Cambridge University Press (August 18, 2003). 
[12] Walsh, S and J.Whalley, 2008.Bringing the Copenhagen climate change negotiations to conclusion, paper presented at CESifo conference on " Europe and Global Environmental Negotiations", July 14-15, 2008.

[13] Whalley, John 1985. Trade liberalization among major world trading areas, MIT Press, Cambridge, Massachusetts, 1985. 